\title{
Identifying Effective Mechanisms to Assist the Marketing Integration Process for Malaysian Acquirers
}

\author{
Mohd Haniff Jedin \\ Universiti Utara Malaysia \\ E-Mail: mdhaniff@uum.edu.my \\ Norsafinas Md. Saad \\ Universiti Utara Malaysia \\ E-Mail: safinas@uum.edu.my
}

\begin{abstract}
Marketing integration in mergers and acquisitions (M\&As) is an important means of ensuring the survival of the combined firm. This can be achieved by streamlining and redeploying all marketing resources from both sides: the acquirer and the acquired firm. Marketing integration could be referred to as the backbone of the firm combining process because of its potential to generate higher revenues for the newly-combined firm. However, existing studies have not clearly investigated the mechanisms that contribute to the marketing integration process in cross-border M\&As. The purpose of this study was to fill this gap by exploring effective mechanisms that can improve this process. Specifically, marketer collaboration, interaction, marketing synergy, and the redeployment of marketing resources were proposed as key mechanisms that influence marketing integration in this context. The results indicated that marketing synergy and the redeployment of marketing resources have a strong and significant impact on the extent of integration. Meanwhile, there is a striking negative and significant result that pertains to the relationship between interaction and speed of integration.
\end{abstract}

Keywords: Marketing Integration, Cross-Border Mergers and Acquisitions 


\section{MARKETING INTEGRATION IN M\&A CONTEXTS}

The marketing integration process in $\mathrm{M} \& \mathrm{~A}$ is defined as combining two marketing departments into one major entity that coordinates and manages all marketing resources of the two firms. The aim is to increase both the extent and speed of the marketing integration process and provide superb M\&A performance. This process does not refer to individual steps, rather proposes mechanisms that can expedite integration and provide benefits to the newly-combined marketing department.

Research and anecdotal evidence has shown that the functional integration of marketing departments is still being neglected, with the notable exception of studies conducted by Griffin and Hauser (Griffin \& Hause, 1996) and Khan and Mentzer (Kahn \& Mentzer, 1998). Many studies on marketing integration have concentrated on the integration between marketing and other functional departments such as sales departments (Guenzi \& Troilo, 2007), R\&D departments (Parry \& Song, 1993), logistics (Ellinger, Daugherty, \& Keller, 2000), communications (Uhlenbruck, Hitt, \& Semadeni, 2006), human resources (Chimhanzi, 2004), and engineering (Lancaster, 1993). However, fewer studies have explored the integration between two similar marketing operations in the context of M\&A. These two exceptions include Capron and Hulland (Capron \& Hulland, 1999) and Homburg and Bucerius (Homburg \& Bucerius, 2005). Due to the lack of previous research, Capron and Hulland (Capron \& Hulland, 1999), studied the redeployment of three marketing resources (i.e., brands, sales forces, and general marketing expertise), with a specific focus on merging firms that followed horizontal, cross-border acquisitions. One objective was to investigate the impact of such redeployments on subsequent performance. Specifically, their research was conducted in 1994 with North American and European manufacturing firms and involved mail survey methods; 253 useable responses were collected out of 1778 surveys that were sent out. The samples were collected from the International Merger Yearbook, the Mergers and Acquisitions Sourcebook, Mergers and Acquisitions International, and Fusions and Acquisitions magazine. According to their findings, all three marketing resources were likely to be redeployed evenly in the M\&A context. Further, Capron and Hulland reported that immobile resources were more likely to be redeployed from the acquired firm compared to more mobile resources. Furthermore, resources were more likely to be redeployed from the acquirer to the acquired firm than they were in the reverse direction. Ultimately, the researchers reported that the redeployment of all three marketing resources positively affected the new firm's performance. 
Homburg and Bucerius (Homburg \& Bucerius, 2005) proposed that marketing-related integration issues, following a merger, such as whether the two firms' marketing activities should be integrated or how these activities affected the performance of the firms after the merger, have not been dealt with in-depth, which has resulted in many potential gaps in the existing knowledge. Homburg and Bucerius conducted a study in 2002 that comprised of firms operating in the German-speaking parts of Central Europe (Germany, Austria, and Switzerland). They also employed survey methods and, from a total of 1483 selected firms, they collected 232 useable questionnaires. Their results indicated that the marketing integration processes significantly affected overall integration outcomes. This finding clearly proves that marketing integration positively affects cost savings and negatively affects market-related performance.

The latest study to investigate the role of marketing functions in creating value in M\&As was that of Vanitha et al. (Vanitha, Feisal, \& John, 2008). They examined when and how similarity and complementarity between merging firms create value under varying merger motives. Using ordinary least squares, Vanitha et al. found that marketing actions, such as consolidating products and markets, can have a positive impact on shareholder value.

The present study attempted to identify effective mechanisms that facilitate the marketing integration process among Malaysian firms that are involved in cross-border M\&As. This paper begins with a discussion of relevant theories that have contributed to the formation of the proposed mechanisms. Next, the model and research hypotheses are presented, after which, we discuss the methodology. We then present our findings. Finally we provide a discussion of the results and our conclusions.

\section{THEORETICAL BACKGROUND}

In this study, the application of resource-based view (RBV) was applied to the redeployment of marketing resources and marketing synergy. Resource-based view is concerned with developing organizational sustainability and improving a competitive advantage by leveraging resources to provide results for the organization's stakeholders (Srivastava, Fahey, \& Christensen, 2001). Further, these mechanisms can be used to expedite the process of marketing integration to achieve better M\&A performance (Zollo \& Singh, 2004; Homburg \& Bucerius, 2005). The redeployment of marketing resources is vital as it is a principle part of operational-level activities within any departmental amalgamation. Specifically, redeployment requires strategies 
that allow marketing departments of the acquiring and acquired firm to exchange information and develop strong marketing personnel (Harrison, Hit, Hoskisson, \& Ireland, 2001). Redeployment may also allow marketing managers to discuss their marketing strengths, promote successful activities and avoid those activities that failed. This is important as it highlights the best marketing strategies and allows the newly-combined marketing department to redeploy its resources in a way that makes the most of its marketing expertise, sales forces, and brands (Capron \& Hulland, 1999).

The arguments in favor of marketing synergy are based on those of Chatterjee (Chatterjee, 1986). For example, Chatterjee proved that collusive synergy is associated with higher value than are either financial or operational synergy. Collusive synergy is achieved when companies with similar industry or departmental backgrounds combine into one entity. The similarity of functional backgrounds may involve the utilization of economies of scale and scope, both in production and distribution. In our study, this was crucial for both the acquiring and the acquired firms: they must make use of synergy across the two marketing departments. All marketing resource synergies, such as advertising, distribution, sales force, and market research are important in the early stages of developing marketing capabilities and proficiencies when building newly-combine firms. Therefore, there is a high tendency for firms to combine their marketing capabilities to better realize the potential of hidden synergies, which also allows newly combined firm to generate more profits via superior marketing activities (Larsson \& Finkelstein, 1999).

At the same time, we introduced interaction and collaboration as core social capital mechanisms, which enhances the marketers' relationship as well as the coordination that is required to achieve a smooth organizational amalgamation (Weiss $\&$ Hughes, 2005). By collaborating and interacting with an M\&A integration, partners can gain benefits by exchanging knowledge and access that might otherwise be unobtainable or extremely costly, such as knowledge of economies, politics, cultures, and business customs. These exchanges allow both the acquiring and acquired firm to put down strong foundations, which could later be crucial to their growth in foreign markets (Sharader, 2001). Moreover, interaction and collaboration are employed as mechanisms that influence interdepartmental integration, particularly when marketing departments interact with other departments, such as manufacturing and research and development (R\&D) (Kahn \& Mentzer, 1998). This was also emphasized by Duysters et al. (Duyster, Kok, \& Vaandrager, 1999), who examined how to establish combination capabilities through building business communities and how to improve 
partner selection, both of which improve interorganizational relationships. In conclusion, our study used RBV theory and social capital theory as the foundation for discussing effective mechanisms (Figure 1) that could influence the marketing integration process and M\&A performance.

\section{RESEARCH HYPOTHESIS}

\section{Collaboration and Interaction}

Collaboration and interaction has been described as a process that involves teams working together and sharing resources via interdepartmental connections (Kahn \& Mentzer, 1998). Meanwhile, interaction refers to any contact or relationship that is directly implemented, be it with customers, staff, or employees, under a particular manager's supervision or those outside of his supervision. Generally, collaboration and interaction are associated with strategic alliances and are used by many organizations in international joint ventures to access rare tangible resources (Cavusgil, Knight, \& Riesenberger, 2008). However, such collaborations are becoming increasingly popular, specifically in the context of M\&As, as a way of gaining access to know-how and other forms of knowledge-based resources. Collaboration has always been described as a process that involves teams working together and sharing resources via interdepartmental connections (Weiss \& Hughes, 2005). Furthermore, collaboration and interaction with foreign partners, through M\&As, can provide firms with knowledge and strategies that might otherwise be extremely costly and difficult to obtain via other cross-border entry modes, such as joint ventures and non-equity alliances (Sharader, 2001). On the one hand, collaboration and interaction, through M\&As, is much easier to realize in terms of control issues, particularly in acquisitions where the acquiring firm will have more say in making important final decisions (Richey, Kiessling, Tokma, \& Dalela, 2008). However, this does not mean that the acquiring firm will have absolute power in managing the new firm, as there are other factors to consider, such as willingness, motivation, and attitudes of the acquired employees regarding their collaboration in the integration process (Faulkner, Pitkethly, \& Child, 2002). In fact, in marketing departments, interactions are implemented through the relationship that a marketing manager has with his subordinates and he or she plays a coordinating role in dealing with the demands of customers and linking with other departments that can satisfy those demands (Ruekert \& Walker, 1987). From these arguments, the following hypotheses relating to collaboration and interaction can be more formally stated. 
Hypothesis 1a (+): The greater the collaboration, the greater the extent of integration.

Hypothesis $1 \mathrm{~b}(+)$ : The greater the collaboration, the greater the speed of integration.

Hypothesis $2 \mathrm{a}(+)$ : The greater the interaction, the greater the extent of integration.

Hypothesis $2 \mathrm{~b}(+)$ : The greater the interaction, the greater the speed of integration.

\section{Redeployment of Marketing Resources}

Following a study conducted by Capron and Hulland (Capron \& Hulland, 1999), the redeployment of marketing resources was defined as use by a target or acquirer of their partner's resources, which may involve a physical transfer of resources to new locations or the sharing of marketing resources without a physical transfer. The redeployment of marketing resources is crucial as it organizes and structures the resources of each party. As is noted by Guenzi and Troilo (Guenzi \& Troilo, 2007), redeployment can help overcome poor firm capacity and marketing capabilities and generate superior customer service. However, this maneuver requires that more attention is placed on the collaborative relationships among marketers as they are the key to developing a smooth alignment process and synchronizing the M\&A marketing integration. Capron and Hulland (Capron \& Hulland, 1999) noted that one benefit of acquisitions is that they remove the need to develop marketing resources, such as brands and sales forces in a new organization, which can be difficult. When a firm acquires another firm, they also acquire its resources, which they can then redeploy as needed. Further, it is believed that this strategy can enhance a firm's competitive position and lead to better financial performance. From these arguments, we proposed that:

Hypothesis 3a (+): The greater the redeployment of marketing resources, the greater the extent of integration.

Hypothesis $3 \mathrm{~b}(+)$ : The greater the redeployment of marketing resources, the greater the speed of integration.

\section{Marketing Synergy}

This study contended that marketing resources and activities across two firms must be effectively managed and leveraged to create strong synergy. Specifically, marketing synergy was defined by Weber and Dholakia (Weber \& Dholakia, 2000), as 
a combination of firms that result in a reduction of duplicated marketing-related resources. In this way, synergistic marketing benefits can be gained by using the available resources from both sides, with the aim of becoming a premier competitor in the market. Marketing resources are a very important means for creating a competitive advantage and consequently boosting a firm's performance (Hooley, Greenley, Cadogan, \& Fahy, 2005). Additionally, synergy is believed to lead to a better combination of products or services, which is important for obtaining new customers and is key to customer retention (Richey, Kiessling, Tokma, \& Dalela, 2008). Thus, the marketers of both the acquiring and the acquired firm need to determine to what extent they should be integrated in order that the resulting marketing synergy enhances the effectiveness of the new marketing strategies of both firms. As such, the first challenge is integration and the second is avoiding overlaps in operations, which would incur unnecessary costs. Therefore, we hypothesized:

Hypothesis 4a (+): The greater the marketing synergy, the greater the extent of integration.

Hypothesis $4 \mathrm{~b}(+)$ : The greater the marketing synergy, the greater the speed of integration.

\section{Extent of Integration}

According to Homburg and Bucerius (Homburg \& Bucerius, 2005), the extent of an M\&A integration can be either low or high. However, the extent (how low or high) of integration does not necessarily mean low (or high) performance. In other words, a deep integration (high extent) is not always the best solution. Moreover, in some cases, costs will be higher than they were before the merger; while, in some areas, integration has the potential to improve M\&A performance. It can also be a means of improving relationships among the combined staff during the integration stage. These relationships are vital: the firms will need to share information (including undisclosed information) as this is the key to a successful integration process (Zhanwen \& Haifeng, 2007). Failure to share information and strategies could jeopardize future performance of the integrated entity. Therefore, we hypothesized:

Hypothesis $5(+)$ : The greater the extent of integration, the better the M\&A performance 


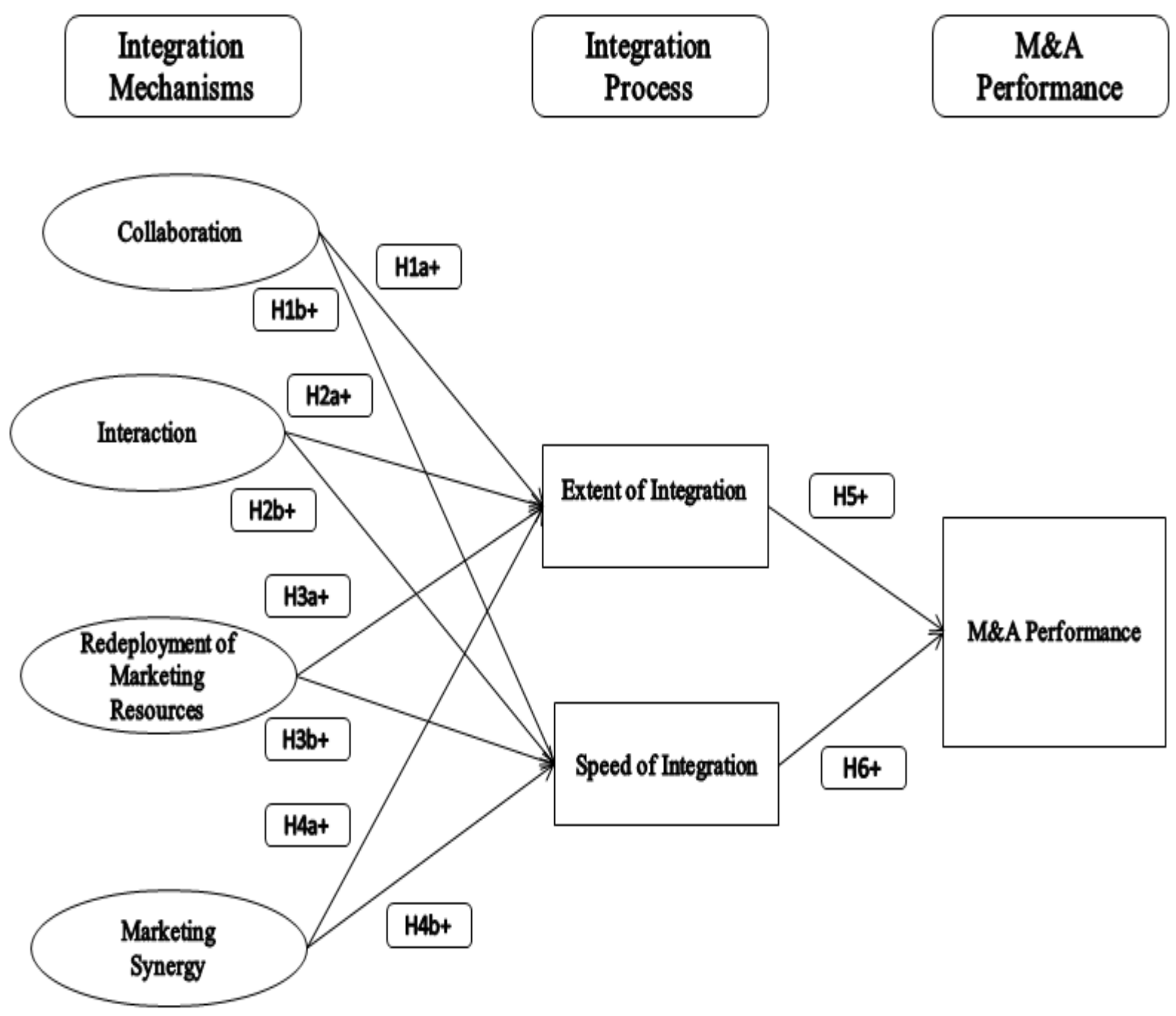

Figure 1 Conceptual Framework of M\&A Marketing Integration

\section{Speed of Integration}

Speed in M\&A integration is associated with decisiveness, gaining an advantage, and time savings (Angwin, 2004). Speed is highly beneficial, particularly in integration processes (Homburg \& Bucerius, 2005) and the speed of integration has been defined as the shortness of time needed to achieve the intended level of marketing integration (Homburg \& Bucerius, 2005). A slow integration process can create problems and the firm can lose the opportunity to take advantage of the energy generated by a M\&A event (Christine \& Brian, 2004). However, according to Schweiger and Goulet (Schweiger \& Goulet, 2000), two opposing arguments are relating to the speed of integration: the slow integration approach and the idea that 
integration should be executed as quickly as possible. In the first argument, it is felt that the acquirer should take the time to get to know the target firm, its staff, culture, operations, and markets, before making any drastic changes. The second argument, however, holds that a quick approach is always more efficient and, most importantly, improves M\&A performance (Cording, Christmann, \& King, 2008). It has also been argued that the quick approach avoids uncertainty about the direction of the new firm and is the best way to reduce any political resistance to change, especially of the target firm. Hadjian (Hadjian, 2000) also took the view that speed of integration is the main positive influence on the performance of a newly-combined firm. Therefore, we hypothesized that:

Hypothesis $6(+)$ : The greater the speed of integration, the better the M\&A performance.

\section{RESEARCH METHODOLOGY}

\section{Sample and Survey Procedure}

A survey methodology was used to collect data in 2008. Specifically, we examined various cross-border M\&A transactions undertaken by Malaysian firms over a period of seven years (2000-2006). This period was chosen because it represented a 'comeback' period for South East Asian countries, especially Malaysia, Thailand, and Indonesia, after the Asian financial turmoil experienced from 1997-1999 (United Nations, World investment report 2000). The M\&A cases were gathered from the Thomson One Banker database. We also confirmed the selected M\&A cases with local stock exchange agencies: the Securities Commission and Bursa Malaysia. In terms of M\&A transaction cases, this study used completed cases (one firm could possibly have more than one M\&A case) (Hunt, 1990). This method was in contrast to a study by Papadakis (Papadakis, 2005), who restricted his sample to only one M\&A per company. The minimum value for a cross border transaction was determined at USD \$1 million, which was lower than the range proposed by Kogut and Singh (Kogut \& Singh, 1988) of USD \$10 million. The rationale behind this was that the currency of countries, such as Malaysia, and the size of firms involved in M\&As in those countries, and most of the transaction values, tended to be lower than those in developed countries. This was also in line with information reported by the Securities Commission of Malaysia, who stated that cases with a value less than USD $\$ 1$ million are usually acquisitioned by internal shareholders and are not likely to involve departmental integration, particularly in cross-border M\&As. Furthermore, if we had adopted a minimum value of USD \$ 10 million, there would have been fewer 
cross-border M\&A cases in Malaysia and we would have been less likely to obtain a good response rate. Further, we only choose firms who acted as acquirers in M\&As and we did not restrict the sample to any specific sector or industry.

Of the 1,697 M\&A cases listed in Thomson One Banker, we identified 250 cases of Malaysian firms that were involved in cross-border M\&As. Selecting only those cases with a transaction value of more than USD \$1 million resulted in 131 cases. From this sample, we managed to collect 97 responses; however, three incomplete responses were discarded, leaving 94 responses, which was equivalent to a nearly $70 \%$ response rate. This response rate was high for several reasons: multiple follow-up methods were applied following Dilman's (Dilman, 2007) tailored design. The most useful collection method was the use of email attachments, followed by in-person collection. As is usually the case, the mail survey response rate was lower than the other methods, although we had supplemented additional questionnaires to encourage respondents to participate. In assessing response bias, we followed the procedure suggested by Armstrong and Overton (Armstrong \& Overton, 1977), which was based on estimating non-response bias via subjective estimates; comparing respondents with non-respondents (using early and late response group); and making comparisons with known values, such as age and income (using t-tests to observe differences between the various data collection methods). Previous M\&A studies have also used this technique by applying it to industry background and the relative sizes of the target and the acquirer (Cording, Christmann, \& King, 2008). The results indicated no significant differences between the groups, that is non-response bias was not an issue and the use of different collection methods did not affect the results.

\section{MEASUREMENT AND ANALYSIS METHOD}

All items in the questionnaire were measured using seven-point Likert scales. Items were adapted from previous empirical research on marketing integration, which mostly related to M\&As. In the effective mechanism, construct items for collaboration and interaction were adapted from Kahn and Mentzer (Kahn \& Mentzer, 1998), marketing synergy from Larsson and Finkelstein (Larsson \& Finkelstein, 1999) and Song et al. (Song, Mitzi, \& Jeffrey, 1997), and items for the redeployment of marketing resources were adapted from Capron and Hulland (Capron \& Hulland, 1999). In the marketing integration process construct, the extent and speed of marketing integration were each adapted from Homburg and Bucerius (Homburg \& Bucerius, 2005). Finally, M\&A performance items were adapted from Colombo et al. (Colombo, Conca, Buongiorno, \& Gnan, 2007). 
The data were analyzed using the partial least squares method (PLS) and applied using the SmartPLS 2.0 software package (Ringle, Sven, \& Alexander, 2005). Partial least squares was employed to analyze the path coefficient by looking at the multiple correlation coefficients ( $\mathrm{R}^{2}$ statistics) for all endogenous constructs (Henseler, Ringle, $\&$ Sinkovics, 2009). Further, PLS was designed to cope with problems in data analysis that are related to small data samples and missing values (Hoyle, 1999). Partial least squares path modeling methods have not only been applied previously in marketing and management research but also more recently to M\&A (see Cording et al. (Cording, Christmann, \& King, 2008)). Item reliabilities were assessed by examining the outer loadings of each item (Table 1), which were above the recommended threshold of 0.7 (Henseler, Ringle, \& Sinkovics, 2009). However, two of the outer loadings were lower than the threshold: new product development (construct: extent of marketing integration) and information systems (construct: speed of marketing integration). In PLS, convergent validity is assessed through internal consistency and discriminant validity (Fornell \& Larcker, 1981; Nunnally, 1978). As such, all internal consistency reliability measures are above the recommended level of 0.70 (Nunnally, 1978). In terms of discriminant validity, Fornell and Larcker (Fornell \& Larcker, 1981) suggested the use of average variance extracted (AVE), which should be greater than each of the variances that are shared between the constructs from the correlation matrix. Table 2 shows that all diagonal elements in the correlation matrix (AVE) were greater than the off-diagonal elements in the corresponding rows and columns (variances shared).

Table 1 Internal Consistency and Items Outer Loading

Construct: Collaboration

\begin{tabular}{lc}
\hline Composite reliability: $\mathbf{0 . 9 3 5 4 2 3} \quad$ Cronbach's alpha: $\mathbf{0 . 9 1 7}$ & Outer Loading \\
\hline We integrate by achieving similar goals. & 0.868 \\
\hline We integrate by having a mutual understanding. & 0.895 \\
\hline We informally work together. & 0.797 \\
\hline We integrate by sharing ideas, information, and resources. & 0.840 \\
\hline We integrate by sharing the same vision of the company. & 0.791 \\
\hline We work together as a team. & 0.851 \\
\hline
\end{tabular}


Table 1 Internal Consistency and Items Outer Loading (Continued)

Construct: Interaction

Composite reliability: $0.894423 \quad$ Cronbach's alpha: 0.847

Outer Loading

\begin{tabular}{ll}
\hline Meetings & 0.786 \\
\hline Committees & 0.811 \\
\hline Phone conversations & 0.837 \\
\hline Electronic mail & 0.861
\end{tabular}

Construct: Redeployment of Marketing Resources

Composite reliability: 0.908499 Cronbach's alpha: $0.878 \quad$ Outer Loading

\begin{tabular}{ll}
\hline We have used the acquired business's sales force. & 0.702 \\
\hline We have used the acquired business's brand(s). & 0.793 \\
\hline We have used the acquired business's marketing expertise. & 0.846 \\
\hline We have transferred the sales force to the acquired business. & 0.766 \\
\hline We have shared the brand(s) with the acquired business. & 0.768 \\
\hline We have transferred the marketing expertise to the acquired Business. & 0.858
\end{tabular}

Construct: Marketing Synergy

Composite reliability: $\mathbf{0 . 9 3 6 1 4 2}$ Cronbach's alpha: $0.918 \quad$ Outer Loading

The similarity of both marketing operations between the joining firms influenced the marketing integration process.

0.777

The complementarity of both marketing operations between the joining firms influenced the marketing integration process.

Both of the joining firms; marketing research resources facilitated the marketing integration process.

Both of the joining firms; sales force resources assisted the marketing integration process.

Both of the joining firms' distribution resources facilitated the marketing integration process.

Both of the joining firms' advertising/promotion resources assisted the marketing integration process. 
Table 1 Internal Consistency and Items Outer Loading (Continued)

\section{Construct: Extent of Integration}

Composite reliability: 0.942831 Cronbach's alpha: 0.929

Outer Loading

Products/services offered (e.g., harmonization of brand names) 0.730

New product development

0.695

Prices (e.g., harmonization of price positioning)

0.782

Communication (e.g., harmonization of advertisement)

0.828

Sales system (e.g., harmonization of sales channels)

0.888

Sales force management (e.g., harmonization of the provision system)

0.893

Information systems (e.g., harmonization of the information systems)

0.866

Internal marketing support

0.867

\section{Construct: Speed of Integration}

Composite reliability: $\mathbf{0 . 9 2 1 2 2 8}$ Cronbach's alpha: 0.920

Outer Loading

Products/services offered (e.g., harmonization of brand names) 0.801

New product development 0.727

Prices (e.g., harmonization of price positioning) 0.872

Communication (e.g., harmonization of advertisement) 0.886

Sales system (e.g., harmonization of sales channels) 0.832

Sales force management (e.g., harmonization of the provision system) 0.890

Information systems (e.g., harmonization of the information systems) 0.687

Internal marketing support

0.726

Construct: Mergers and Acquisitions Performance

Outer Loading

Composite reliability: 0.935757 Cronbach's alpha: 0.912

\begin{tabular}{ll}
\hline Market share & 0.904 \\
\hline Profitability (return on investment) & 0.869 \\
\hline Competitive position & 0.905 \\
\hline Market coverage & 0.921 \\
\hline Customer satisfaction & 0.701
\end{tabular}

\section{RESULTS}

The hypotheses were tested by estimating the path coefficient effects and $\mathrm{R}^{2}$ values. The estimated path coefficient effects indicated the strengths of the relationships between the dependent and independent variables (Sheng-Hsun, H., Wun-Hwa, C., \& Ming-Jyh, H., 2006). The $\mathrm{R}^{2}$ (squared multiple correlations) values 
showed the amount of variance explained by each of the independent variables (Chin, W. W., Marcolin, B. L., \& Newsted, P. R., 2003). We also assessed the path significance level by employing the bootstrapping method of Smart PLS 2.0 (M3) (Ringle, Sven, \& Alexander, 2005). Figure 2 shows the results of the hypothesis testing. We will now discuss the results in terms of the type of relationship: relationships between proposed effective mechanism and marketing integration process and relationships between marketing integration process and M\&A performance.

\section{Relationship between Effective Integration Mechanisms and Marketing Integration Process}

Figure 2 shows the estimated path coefficients, highlighting those that confirmed a relationship between the mechanism in question and the marketing integration process. Four latent variables were proposed: collaboration, interaction, redeployment of marketing resources and marketing synergy. Two of the eight proposed hypotheses are supported. Marketing synergy was shown to have a positive effect that significantly influenced the extent of marketing integration $(b=0.291, p<0.001)$. Hence, hypothesis H4a was supported. Similarly, hypothesis H3a was supported: the redeployment of marketing resources was found to have a positive and significant influence on the extent of marketing integration $(b=0.450, p<0.001)$.

In contrast, neither of the collaboration constructs were significant in predicting the extent of marketing integration; that is, H1a $(b=0.108, p=n . s)$ and H1b $(b=$ $0.069, \mathrm{p}=\mathrm{n} . \mathrm{s}$ ) were not supported. Turning to the interaction constructs, hypothesis $\mathrm{H} 2 \mathrm{~b}$ was not supported $(\mathrm{b}=-0.245, \mathrm{p}<0.05)$ because the interaction was significant, but negatively related, to the speed of marketing integration. Additionally, $\mathrm{H} 2 \mathrm{a}$ ( $\mathrm{b}=$ $0.018, \mathrm{p}=\mathrm{n} . \mathrm{s}$ ) was not supported and no significant relationship was found between interaction and the extent of integration. The remaining two proposed hypotheses, $\mathrm{H} 3 \mathrm{~b}(\mathrm{~b}=-0.104, \mathrm{p}=\mathrm{n} . \mathrm{s})$ and H4b (b=-0.067, $\mathrm{p}=\mathrm{n} . \mathrm{s})$ were also not supported, as the relationships in question were not significant ( $\mathrm{n} . \mathrm{s}=$ not significant).

\section{Relationships between the Marketing Integration Process and M\&A Performance}

The extent of integration yielded a significant and positive effect on M\&A performance $(\mathrm{b}=0.642, \mathrm{p}=0.001)$. Thus, hypothesis $\mathrm{H} 5$ was confirmed. However, the speed of integration was significant but negatively associated with M\&A performance $(b=-0.199, p=0.05)$; meaning that hypothesis H6 was not confirmed. 


\section{DISCUSSION AND IMPLICATIONS}

This study demonstrated that the redeployment of marketing resources has a highly significant, positive influence on the extent of marketing integration (H3a). In other words, it appears that, if both the acquirer and the target firm work together to improve their marketing departments, by sharing and exchanging marketing resources, they can enhance marketing integration. This statement indicates that, when firms combine, particularly in M\&As, marketers must adjust, restructure, and look for new paradigms to utilize the available marketing resources on both sides. This should include optimizing and exchanging marketing resources and absorbing new knowledge (Zollo \& Singh, 2004). Overall, doing so will gradually improve trust and create value in the M\&A and, ultimately, develop a spirit of belonging among the marketers in the newly-combined firm. This finding is consistent with studies conducted by Capron and Hulland (Capron \& Hulland, 1999) and Krishnan et al. (Krishnan, Joshi, \& Krishnan, 2004).

The present study also showed that marketing synergy is significantly and positively associated with the extent of marketing integration ( $\mathrm{H} 4 \mathrm{a})$. This finding suggests that both the acquirer and the target firm must diagnose and then select several of their best marketing practices that can be employed in both countries to expedite strategic profit goals. In fact, Weber and Dholakia (Chimhanzi, 2004) also emphasized that the determining factors in the success of a combination of two firms, particularly in a M\&A, come from marketing synergies. This is important as both the acquirer and the target firm can employ superior marketing activities that are drawn from each other's marketing strategies, which could possibly lead to a better marketing strategy for both firms. This result is in line with a study conducted by Vanitha et al. (Vanitha, Feisal, \& John, 2008) and is also known as strategic emphasis alignment. The strategic components, emphasized by the acquirer and target firm, can be similar to or distinct from one another. 
Table 2 Correlations and Discriminant Validity

\begin{tabular}{lccccccc}
\hline Latent Variables & $\mathbf{1}$ & $\mathbf{2}$ & $\mathbf{3}$ & $\mathbf{4}$ & $\mathbf{5}$ & $\mathbf{6}$ & $\mathbf{7}$ \\
\hline 1 Collaboration & $\mathbf{0 . 8 4 1}$ & & & & & & \\
\hline 2 Extent of integration & 0.440 & $\mathbf{0 . 8 4 0}$ & & & & & \\
\hline 3 Interaction & 0.502 & 0.431 & $\mathbf{0 . 8 3 5}$ & & & & \\
\hline 4 M\&A Performance & 0.509 & 0.673 & 0.574 & $\mathbf{0 . 8 6 4}$ & & & \\
\hline 5 Marketing Synergy & 0.499 & 0.505 & 0.653 & 0.504 & $\mathbf{0 . 8 4 3}$ & & \\
\hline $\begin{array}{l}\text { 6 Redeployment of Marketing } \\
\text { Resources }\end{array}$ & 0.395 & 0.627 & 0.694 & 0.437 & 0.659 & $\mathbf{0 . 7 9 0}$ & \\
\hline 7 Speed of integration & -0.132 & -0.064 & -0.094 & -0.292 & -0.279 & -0.237 & $\mathbf{0 . 8 2 3}$ \\
\hline
\end{tabular}

* Bold diagonal figures represent the square root of AVE

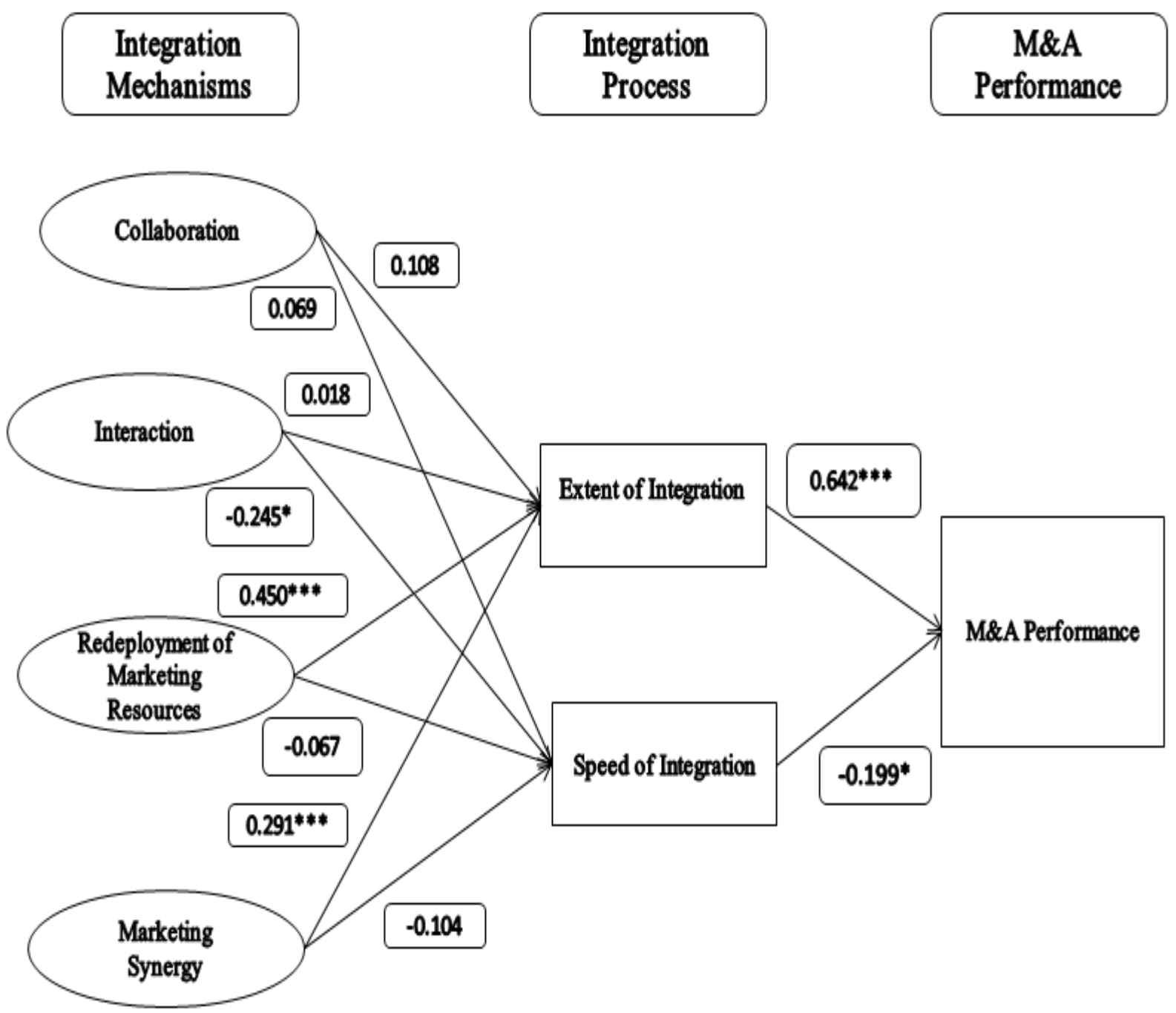

Figure 2 Path estimation of M\&A marketing integration 
Both predictors were based on RBV, which means that the acquiring and acquired firms must restructure and manage their marketing resources, which are the key to successful marketing integration processes. Another perspective indicates that managing marketing resources should come first, before generating particular relationships through social capital foundations (Srivastava, Fahey, \& Christensen, 2001). However, this does not mean that social interaction and collaboration are not important. Rather, firms must gather information about their marketing strategies and strengths and format a plan to combine them to create synergy, which acts as a major foundation for building sturdy relationships. Therefore, it is clear that our first question, pertaining to effective mechanisms, was answered: the redeployment of marketing resources and marketing synergy are keys to successful marketing integration processes in cross-border M\&As.

Nevertheless, another striking result from this paper is that there is a significant but negative relationship between interaction and the speed of marketing integration. This suggests that the interaction between the acquiring and acquired firms is important; however, over interaction can reduce the speed of such interactions. This could be because more interaction often leads to an increase in the number of rumors and, as a result, creates irrational dissatisfaction about possibilities such as cost cutting and staff reductions during the integration process (Sinkin \& Putney, 2009). A study by Ruekert and Walker Jr (Ruekert \& Walker, 1987) confirms this theory. Specifically, they found that the degree of conflict increases if the level of interaction between marketing personnel and other functional areas increase.

As for the non-significant variables, collaboration was found to influence neither the speed nor the extent of integration $(\mathrm{H} 1 \mathrm{a}$ and $\mathrm{H} 1 \mathrm{~b})$, interaction did not significantly affect the extent of integration ( $\mathrm{H} 2 \mathrm{a})$, and marketing synergy (H3b) and the redeployment of marketing resources $(\mathrm{H} 4 \mathrm{~b})$ did not influence speed. Collaboration is generally thought to significantly and positively influence the marketing integration process. However, our results suggest that collaboration between the marketers of the acquirer and the target firm has no effect. Of note, the marketers of both the acquirer and the target firm do seem to collaborate; however, this was not as influential as the restructuring of marketing resources. One reason for this result may be the differences in marketing practices in cross-border environments, which presented a gap, thus, discouraging collaboration in marketing activities in comparison to other effective mechanisms.

With these results, we have achieved our main objective; demonstrate that the redeployment of marketing resources and marketing synergy are key mechanisms for 
ensuring a successful marketing integration process in a cross-border M\&A. Interaction was also found to be important but the indications are that less interaction is better, especially with regard to decision making and information flow during the integration process.

\section{CONCLUSION}

In conclusion, the marketing integration process in cross-border M\&As is a very crucial area, as it determines whether the combined firm will improve its sustainability and growth, particularly at the international level. Most cases that have been studied have failed to prevail in this task. Most importantly, the goals of the combined firm are not simply to generate more profit or achieve a better market share but to help establish reputable bilateral relationships between the two countries involved. This, in turn, can eventually create a strong basis for structured and organized corporate governance, which could stabilize the combined firm in the long run. Further, RBV, as the main theory behind the effective mechanisms developed in this paper, offers a clear understanding of how marketing integration supplements the M\&A integration process. In particular, a better marketing strategy can increase the sales and revenues of the combined firm, which can be achieved via a comprehensive marketing restructure and the redeployment of marketing resources. In turn, this will stimulate the integration process as a whole and thereby boost M\&A performance. While RBV has been identified as the main theory contributing to this study, further refinements are needed. Perhaps future research should attempt to identify other effective mechanisms that could facilitate marketing integration processes in cross-border M\&A. For example, Garret et al. (Garrett, Buisson, \& Yap, C. M., 2006) proposed four factors: formalization, centralization, role flexibility, and inter-functional climate that boost the integration between a marketing department and a R\&D department, eventually improving new product development. Nevertheless, this study also has a few limitations: its scope was marketing departments and, thus, the results cannot be generalized to other departments, and its placement within the Malaysian context. Future studies could extend this work to other Asian countries, such as Singapore, Indonesia, and Thailand and also make comparisons between countries. 


\section{REFERENCES}

Angwin, D. (2004). Speed in M\&A integration: the first 100 days. European Management Journal, 22(4), 418-430.

Armstrong, J. S. \& Overton, T. S. (1977). Estimating non-response bias in mail surveys. Journal of Marketing Research, 14(3), 396-402.

Capron, L. and Hulland, J. (1999). Redeployment of brands, sales forces, and general marketing management expertise following horizontal acquisitions: a resource-based view. Journal of Marketing, 63(2), 41-54.

Cavusgil, T., Knight, G. \& Riesenberger, J. (2008). International business: strategy, management and the new realities. New Jersey: Pearson Education.

Chatterjee, S. (1986). Types of synergy and economic value: the impact of acquisitions on merging and rival firms. Strategic Management Journal, 7(2), 119-139.

Chimhanzi, J. (2004). The impact of integration mechanisms on marketing/HR Dynamics. Journal of Marketing Management, 20(7/8), 713-740.

Chin, W. W., Marcolin, B. L. \& Newsted, P. R. (2003). A partial least squares latent variable modelling approach for measuring interaction effects: results from a Monte Carlo simulation study and an electronic-mail emotion/adoption Study. Information Systems Research, 14(2), 189-217.

Christine, T. W. H. \& Brian, H. K. (2004). New developments concerning managing mergers and acquisitions. Management Research News, 27(4/5), 54-63.

Colombo, G., Conca, V., Buongiorno, M. \& Gnan, L. (2007). Integrating cross-border acquisition: a process-oriented approach. Long Range Planning, 40(2), 202-222.

Cording, M. P., Christmann, P. \& King, D. R. (2008). Reducing causal ambiguity in acquisition integration: intermediate goals as mediators of integration decisions and acquisition performance. Academy of Management Journal, 51(4), 744-767.

Dilman, D. A. (2007). Mail and internet surveys 2007: with new internet, visual and mixed-mode guide: the tailored design method. New Jersey: Wiley and Sons.

Duysters, G., Kok, G. \& Vaandrager, M. (1999). Crafting successful strategic technology partnerships. R\&D Management, 29(4), 343-351.

Ellinger, A. E., Daugherty, P. J. \& Keller, S. B. (2000). The relationship between marketing/logistics interdepartmental integration and performance in U.S manufacturing firms: An empirical study. Journal of Business Logistics, 21(1), $1-22$. 
Faulkner, D., Pitkethly, R. \& Child, J. (2002). International mergers and acquisitions in the UK 1985 -1994: a comparison of national HRM practices. International Journal of Human Resource Management, 13(1), 106-122.

Fornell, C. \& Larcker, D. F. (1981). Evaluating structural equation models with unobservable variables and measurement error. Journal of Marketing Research, 18(1), 39-50.

Garrett, T. C., Buisson, D. H. \& Yap, C. M. (2006). National culture and R\&D and marketing integration mechanisms in new product development: a cross-cultural study between Singapore and New Zealand. Industrial Marketing Management, 35(3), 293-307.

Griffin, A. \& Hauser, J. R. (1996). Integrating R\&D and marketing: a review and analysis of the literature. Journal of Product Innovation Management, 13(3), 191-215.

Guenzi, P. \& Troilo, G. (2007). The joint contribution of marketing and sales to the creation of superior customer value. Journal of Business Research, 60(2), 98-107.

Hadjian, A. L. (2000). Speed: what it takes to make mergers work. Investment Dealers' Digest, 66(31), 11.

Harrison, J. S., Hitt, M. A., Hoskisson, R. E. \& Ireland, R. D. (2001). Resource complementarity in business combinations: extending the logic to organizational alliances. Journal of Management, 27(6), 679-690.

Henseler, J., Ringle, C. M. \& Sinkovics, R. R. (2009). The use of partial least squares path modelling in international marketing. Advances in International Marketing, 20, 277-319.

Homburg, C. \& Bucerius, M. (2005). A marketing perspective on mergers and acquisitions: how marketing integration affects post-merger performance. Journal of Marketing, 69(1), 95-113.

Hooley, G. J., Greenley, G. E., Cadogan, J. W. \& Fahy, J. (2005). The performance impact of marketing resources. Journal of Business Research, 58(1), 18-27.

Hoyle, R. H. (1999). Statistical Strategies for Small Sample Research. London: Sage Publications Inc.

Hunt, J. W. (1990). Changing pattern of acquisition behaviour in takeovers and the consequences for acquisition processes. Strategic Management Journal, 11(1), 69-77.

Kahn, K. B. \& Mentzer, J. T. (1998). Marketing's integration with other departments. Journal of Business Research, 42(1), 53-62. 
Kogut, B. \& Singh, H. (1988). The effect of national culture on the choice of entry mode. Journal of International Business Studies, 19(3), 411- 432.

Krishnan, R. A., Joshi, S. \& Krishnan, H. (2004). The influence of mergers on firms' product-mix strategies. Strategic Management Journal, 25(6), 587-611.

Lancaster, G. (1993). Marketing and engineering: Can there ever be synergy? Journal of Marketing Management, 9(2), 141-153.

Larsson, R. \& Finkelstein, S. (1999). Integrating strategic, organizational, and human resource perspectives on mergers and acquisitions: a case survey of synergy realization. Organization Science, 10(1), 1-26.

Nunnally, J. (1978). Psychometric Methods. New York: McGraw Hill.

Papadakis, V. M. (2005). The role of broader context and the communication program in merger and acquisition implementation success. Management Decision, 43(2), 236-255.

Parry, M. E. \& Song, X. M. (1993). Determinants of R\&D-marketing integration in high-tech Japanese firms. Journal of Product Innovation Management, 10(1), 4-22.

Richey, R. G., Kiessling, T. S., Tokma, M. \& Dalela, V. (2008). Market growth through mergers and acquisitions: the role of the relationship marketing manager in sustaining performance. Industrial Marketing Management, 37(4), 394-406.

Ringle, C. M., Wende, S., \& Will, A. (2005). SmartPLS 2.0 M3. Retrieved April 08, 2011, from http:// www.smartpls.de

Ruekert, R. W. \& Walker, J. O. C. (1987). Interactions between marketing and R\&D departments in implementing different business strategies. Strategic Management Journal, 8(3), 233-248.

Schweiger, D. M. \& Goulet, P. K. (2000). Integrating mergers and acquisitions: An international research review. Advances in Mergers and Acquisitions, 1, 61-91.

Sheng-Hsun, H., Wun-Hwa, C. \& Ming-Jyh, H. (2006). Robustness testing of PLS, LISREL, EQS and ANN-based SEM for measuring customer satisfaction. Total Quality Management \& Business Excellence, 17(3), 355-371.

Sharader, R. C. (2001). Collaboration and performance in foreign markets: the case of young high-technology manufacturing firms. Academy of Management Journal, 44(1), 45-60.

Sinkin, J. \& Putney, T. (2009). Keeping it together. Journal of Accountancy, 207(4), 24-28. 
Song, X. M., Mitzi, M. M.-W. \& Jeffrey, B. S. (1997). The role of marketing in developing successful new products in South Korea and Taiwan. Journal of International Marketing, 5(3), 47-69.

Srivastava, R. K., Fahey, L. \& Christensen, H. K. (2001). The resource-based view and marketing: the role of market-based assets in gaining competitive advantage. Journal of Management, 27(6), 777-803.

Uhlenbruck, K., Hitt, M. A. \& Semadeni, M. (2006). Market value effects of acquisitions involving internet firms: a resource-based analysis. Strategic Management Journal, 27(10), 899-913.

UNCTAD (2000). World investment report 2000: Cross-border mergers and acquisitions and development overview. Transnational Corporation, 9(3), 99-135.

Vanitha, S., Feisal, M. \& John, H. (2008). Value creation following merger and acquisition announcements: the role of strategic emphasis alignment. Journal of Marketing Research, 45(1), 33-47.

Weber, J. A. \& Dholakia, U. M. (2000). Including marketing synergy in acquisition analysis: a step-wise approach. Industrial Marketing Management, 29(2), 157-177.

Weiss, J. \& Hughes, J. (2005). Want collaboration? Harvard Business Review, 83(3), 93-101.

Zhanwen, Z. \& Haifeng, H. (2007). The cultural integration in the process of cross-border mergers and acquisitions. International Management Review, 3(2), 40-44.

Zollo, M. \& Singh, H. (2004). Deliberate learning in corporate acquisitions: post-acquisition strategies and integration capability in U.S Bank Mergers. Strategic Management Journal, 25(13), 1233-1256. 